\title{
Compensation of Voltage disturbances in hybrid AC/DC Microgrids using series converter
}

\author{
Saeed Daneshvar Dehnavi*,1, Ehsan Shayani² \\ ${ }^{1}$ Department of Electrical Engineering Marvdasht Branch, Islamic Azad University, Marvdasht, \\ Iran \\ ${ }^{2}$ Department of Electrical Engineering Dezfool Branch, Islamic Azad University, Khuzestan, Iran \\ " Corresponding author: Email: Sdaneshvard@gmail.com
}

\begin{abstract}
In this paper a series power electronic converter is proposed to improve power quality of $A C / D C$ hybrid microgrids. An injection transformer which is series with AC microgrid is used beside the series converter to inject voltage for the purpose of voltage disturbances compensation. The series converter by using a simple and effective control system in stationary reference framework of $d-q-0$ is proposed to compensate voltage sag and swell, source unbalanced voltages, voltage harmonics of the utility. In these types of micrigrids a lot of voltage disturbances have occurred due to large number of converters. Moreover, it is not required to use a storage energy system like battery; the required power is supplied by DC microgird, so the proposed system is very efficient. Simulation results in the MATLAB/Simulink environment have verified the appropriate performance of the proposed method.
\end{abstract}

Keywords: Microgrids, Power Quality, Voltage improvement, Series Converter 


\section{Introduction}

$\mathrm{N}$ Nowadays, because of the environmental issues and dangerous effects which are caused by fossil fuel power plants, distributed generation (DG) units have been proposed in the low voltage systems. Most of DG types are renewable energy [1]. Because of the increasingly need to DGs and main concerns regard to DGs power management, a new framework of active network or Microgrid (MG) should be provided to connect the DGs to the distribution systems. Operation of MG has two modes: grid-connected mode and island mode. Because most of the renewable energy resources generate DC power [2-3], recently the operation of DC loads has taken a new form; so need for DC microgrids is a possible solution [4-5]. Moreover, because most of the networks structures support AC power, these types of MGs are becoming the main part of the power systems [6-7]. A hybrid MG AC/DC is defined recently and researches about its optimal operation continue. Interface of two MG are formed by two-side AC/DC converters which are connected together [8]. Because of the AC to $\mathrm{DC}$ or DC to AC and large number of converters, it is required to implement control strategies in these MGs to improve power quality [9]. According to IEEE 1900 Standard, power quality is defined to improve supply and protection of the equipment. One of the main parameters of the system is the Voltage unbalance which has adverse effect on the system. The unbalance voltage increases the losses, reduces the stability, and damages equipment such as motors, power electronic converters and speed regulator drives [10]. Compensation of voltage unbalance usually is performed by active filter which inject negative sequence voltage in series with distribution line [11-12]. There are the other methods to compensate voltage unbalance. For example in [13-14] unbalance voltage compensation is performed by balanced line currents. Because of the high amplitude of these currents in loads, this method has been faced with serious problems. One of the most important methods for unbalance voltage compensation is Dynamic voltage recovery (DRV) method. The main problem of this type of D-FACTS devices is that they need to storage elements like batteries, Super capacitors, diode converter with a parallel capacitance and etc. [15]. In some researches renewable energy resources such as solar energy are used to supply the required power [16]. For example in [17] solar energy is used replace conventional energy resources. In this paper a series converter is used to connect AC Microgrid and DC microgrid and compensate the voltage disturbances. The main difference of proposed method and DVR is that the proposed method does not need to power generation resource for its power; because the required power is supplied by the DC bus and a voltage injection transformer which is in series with network. Moreover, it is possible to clear intensive faults which require to more active

\section{THE PROPOSED TOPOLOGY}

power.

The proposed topology is shown in figure 1. In this figure the series power electronic converter is placed between the $\mathrm{AC}$ and $\mathrm{DC}$ microgrids so that the required power for the voltage disturbance compensation is supplied by the DC microgrid. Therefore, the advantage of this method is that the large voltage drops which requires high power could be compensate in a suitable way. Moreover, an efficient controller is designed to detect the voltage disturbances, inject voltage and detect the final error. The appropriate performance of the under study series converter and its controller is indicated in MATLAB/Simulink environment.

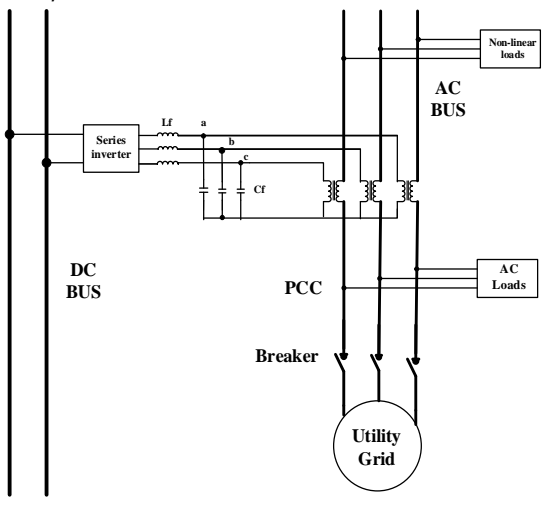

Fig. 1.- The proposed AC/DC hybrid Microgrids. 


\section{CALCULATION}

3.1 Calculation of the injected voltage of series converter for voltage compensation based on the power injection

Let us consider the thevenin equivalent circuit of the network and series converter and their single line diagram according to figures 2 and 3. Converter voltage is determined as:

And IL is obtained as:

$\boldsymbol{I}_{L}=\left[\frac{\boldsymbol{p}_{L}+j \boldsymbol{Q}_{L}}{\boldsymbol{V}_{L}}\right]^{*}$

If the load voltage phase is equal to zero, the equation () is written as:

Where $\alpha, \beta$, and $\delta$ are the angles of Vse, Zth, and Vth, respectively and $\theta$ is the load power factor angle which is expressed as:

$$
\theta=\tan ^{-1}\left(Q_{L} / P_{L}\right)
$$

The injected apparent power of series converter is determined as:

$$
S_{s e}=V_{s e} I_{L}^{*}
$$

If the angle between Vse and IL is kept vertical, the injected active power for voltage compensation will be zero and only the reactive power will be injected by the series converter. It should be mentioned that the series converter performance without active power injection is justifiable if the power shortage could be compensated; otherwise, the active power injection is inevitable. The active power injection of series converter is provided by DC microgrid. Hence reduction in injected voltage amplitude by series converter leads to voltage correction with minimum active power injection. In this method voltage correction is so effective in reduction in capacity and value of series converter booster transformers [18].

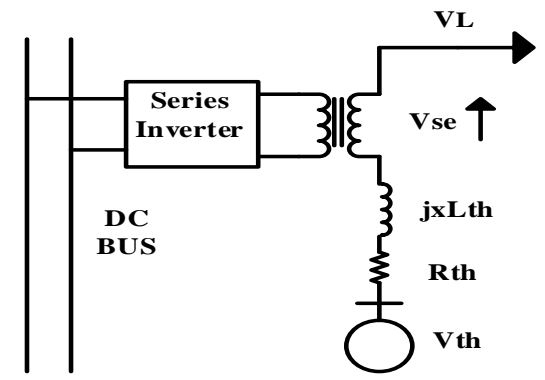

Fig. 2 Thevenin equivalent circuit of network and series converter

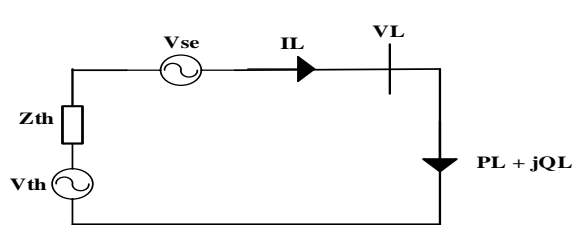

Fig. 3: Single line diagram of Thevenin equivalent circuit of network and series converter

3.2 Series converter interface performance without active power injection

As it has been mentioned previously, $(1)$ the angle between Vse and IL must be 90 to compensate the voltage without active power injection. Therefore, angle of Vse $\alpha$ is determined as:

$$
\alpha=90-\theta
$$

And $\alpha$ is obtained as:

$$
\alpha=\tan ^{-1}\left[\frac{z_{t h}{ }^{I} \operatorname{Sin}(\beta-\theta)-V_{t h} \sin \delta}{V_{L}+Z_{t h}{ }^{I} \cos (\beta-\theta)-V_{t h} \cos \delta}\right]
$$

Considering (6) and (7), we have:

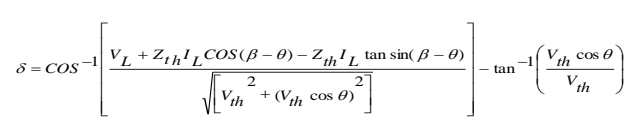

According to (8), the requirement for the (5) answer for $\delta$ is:

$$
\left[\frac{V_{L}+Z_{t h}{ }^{I} L \cos (\beta-\theta)-Z_{t h}{ }^{I} L}{\tan \sin (\beta-\theta)}\right] \leq 1
$$

By simplifying (9), answer condition for $\delta$ is determined as:

$$
V_{t h} \geq\left(V_{L} \operatorname{COS} \theta+Z_{t h} I_{L} \operatorname{COS} \beta\right)
$$

The right side of (10) is depended on load current, load voltage, and system impedance. The calculated

Vth indicates the voltage correction without active power injection.

\subsection{Series converter interface performance} by minimum active power injection for voltage injection

Given load current, power injection of series converter is depended on the injected voltage amplitude which can be obtained as:

$V_{s e}^{2}=V_{L}^{2}+V_{t h}^{2}+Z_{t h}^{2} I_{L}^{2}+V_{L} Z_{t h} I_{L} \operatorname{COS}(\beta-\theta)-2 V_{t h} Z_{t h} I_{L} \operatorname{COS}$

$(\beta-\theta-\delta)-2 V_{L} V_{t h} \operatorname{COS} \delta$

Therefore for the minimum voltage injection (or power injection) the following condition must be provided:

$\frac{\delta V^{2} D V R}{\partial \delta}=o$

So $\delta$ is obtained as: 
$\delta=\tan ^{-1}\left[\frac{z_{t h}{ }^{I} L^{\sin (\beta-\theta)}}{V_{L}+Z_{t h}{ }^{I} L^{\operatorname{CoS}(\beta-\theta)}}\right]$

Given $\delta$, voltage and power injection of series converter is obtained.

\section{CONTROL OF THE SERIES INVERTER}

The main performance of the series converter is to inject dynamic controlled voltage (Vinj) to the voltage bus. This is done by injection transformer. Instantaneous amplitude of injected voltage in 3 phases is controlled so that the destructive effect of bus error on the load voltage (VL) will be avoided. It means that every voltage difference caused by disturbances in the AC microgrids is compensated by an equal voltage. The performance of the series converter is not depended on the error type and system events. The series power electronic converter has to operation modes. a) Standby: in this mode of compensation (Vinj=0) low voltage winding transformer of voltage converter is short circuit. In this mode, no switching occurs in semiconductor equipment, because inverter terminals are triggered so that the short circuit path will be provided for the transformer connection. Series power electronic converter mostly is in this operation mode. b) Compensation: in this mode (Vinj $>0$ ) the series converter injects compensation voltage by voltage injection transformer with detection of disturbance in the power supply. Figure 4 shows the circuit diagram block of the series compensation control using synchronous framework.

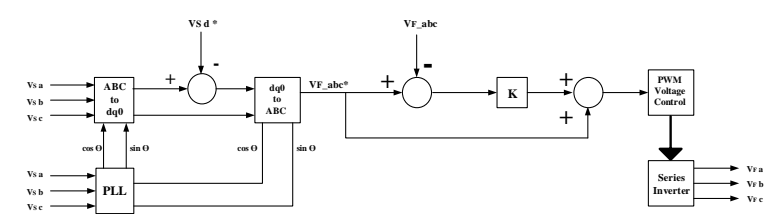

Fig. 4: Circuit block diagram of the series converter control.

In this method, harmonics, sag and swell, negative and zero sequences, and unbalanced in voltage could be extracted. This method could be used in sinusoidal, non-sinusoidal, symmetrical, non-symmetrical waveforms. In the method of synchronous reference framework theory, first the system voltage A-B-C with synchronous reference framework is converted to the $\mathrm{d}-\mathrm{q}-0$ coordinate system according to (14)

$V_{s d q 0}=T_{a b c}^{d q 0} \quad V_{s a b c}$
In typical methods undesirable parts of $\mathrm{q}$ and(13) d voltages are eliminated using low-pass and high-pass filters. Then compensation voltages are obtained using synchronous framework conversion. This method leads to phase shift and changes in amplitudes of harmonics that are passing from the filters. In this method low-pass and high-pass filters are replaced by desirable value of load phase voltage in $d$ and $q$ coordinates. Load voltage must be completely sinusoidal with fixed frequency and amplitude. Desirable voltage and expected load are determined as equations 15 and 16.

$$
\begin{aligned}
& V_{l a b c}^{*}=T_{a b c}^{d q 0} \quad V_{\text {labc }}^{*}=\left[\begin{array}{c}
V_{m} \\
0 \\
0
\end{array}\right] \\
& V_{l a b c}^{*}=\left[\begin{array}{c}
V_{m} \cos (\omega t+\theta) \\
V_{m} \cos (\omega t+\theta-120) \\
V_{m} \cos (\omega t+\theta+120)
\end{array}\right]
\end{aligned}
$$

Where $\mathrm{Vm}$ is the desirable load peak value and $\theta$ is the voltage angle which is calculated by PLL; this angle is obtained by subtracting the phase voltage desirable value in $\mathrm{d}$ coordinate axis $\mathrm{V} \mathrm{d}^{*}$ from $\mathrm{V}_{\text {sd }}$ all the disturbances in $\mathrm{d}$ axis. Moreover the load phase voltage desirable value in $\mathrm{q}$ axis is equal to zero. In other word, Vsd indicates all the disturbances of the $q$ axis. Hence series compensation reference is calculated as:

$V_{L d}^{*}=V_{L d}-V_{L d} \sim$

Then after the conversion to ABC the calculated disturbance voltage is:

$V_{A B C 1}=V_{A B C}^{*}-V_{\text {invert }}$

This value is subtracted from the converter voltage, then is compared with triangular waveform by PI controller in Pulse width modulation (PWM); finally required control pulses $g_{1}-g_{6}$ are generated to impose to the series voltage converter switches. The modified method is programmable with low cost. The other advantage is that the calculation time of the control circuit is reduced, so the pulse time of the control system will be faster.

\section{SIMULATION RESULTS}

A case study that is shown in figure 1 is employed to verify the performance of the proposed series converter in AC/DC hybrid microgrids. The required parameters are shown in table 1. 
Table 1: Network Specification

\begin{tabular}{|l|c|}
\hline Parameter & Value \\
\hline AC microgrid Voltage & $380 \mathrm{~V}$ \\
\hline DC microgrid Voltage & 500 \\
\hline $\begin{array}{l}\text { Conversion ratio of the } \\
\text { injection transformer }\end{array}$ & $1: 1$ \\
\hline Load active power & $10 \mathrm{kw}$ \\
\hline Load reactive power & $3 \mathrm{kvar}$ \\
\hline Network frequency & $50 \mathrm{~Hz}$ \\
\hline Filter inductance & $7 \mathrm{MH}$ \\
\hline Filter inductance & $50 \mu \mathrm{F}$ \\
\hline Switching frequency & $10 \mathrm{kHz}$ \\
\hline
\end{tabular}

5.1 Simulation results of balanced voltage sag in utility:

To evaluate the performance of the proposed method, balanced voltage sag is imposed from the network side. This sag is imposed in $0.2 \mathrm{~s}$ to $0.3 \mathrm{~s}$ with $0.5 \mathrm{pu}$. figure 5 -a shows the voltage at PCC, figure 5-b shows the injected voltage of series converter, and figure 5-c shows the modified load voltage.

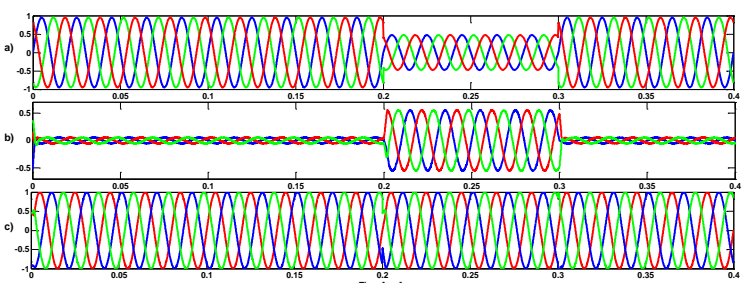

Fig.5

Injected active and reactive power for drop voltage compensation of three phase balanced fault are shown in figures 6-a and 6-b.

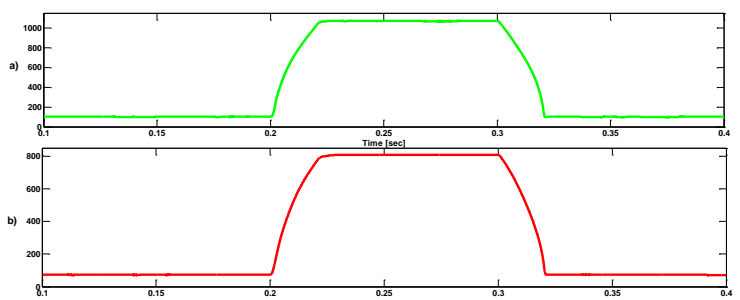

Fig. 6

5.2 Simulation result of voltage swell on utility voltage

Figure 7-a shows the voltage at PCC, figure 7$b$ shows the injected voltage of series converter, and figure 7-c shows the modified load voltage. This voltage swell is imposed in 0.2s to 0.3s. Simulation results are shown in the figure.

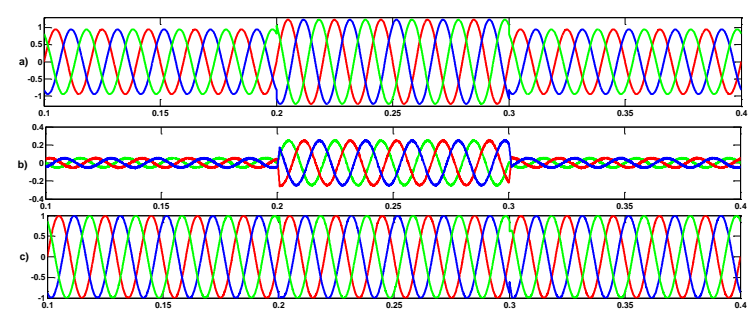

Fig. 7

Figure 8-a and 8-b show the active and reactive injected power for swell voltage compensation.

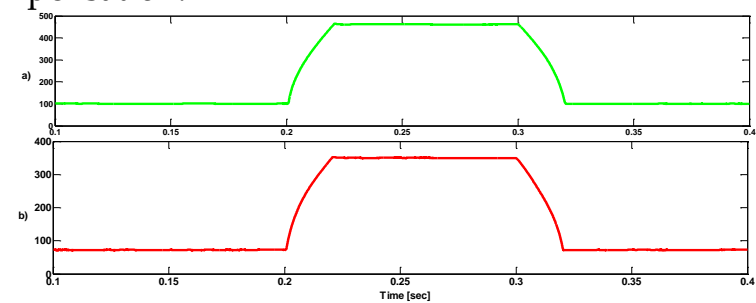

Fig. 8

5.3 Simulation results of unbalanced on utility voltage

Figure 9-a shows the voltage at PCC, figure 9$\mathrm{b}$ shows the injected voltage of series converter, and figure 9-c shows the modified load voltage. This unbalanced voltage occurred in angle of -45 and amplitude of $0.5 \mathrm{pu}$ and negative sequence. Simulation results are shown in the figure.

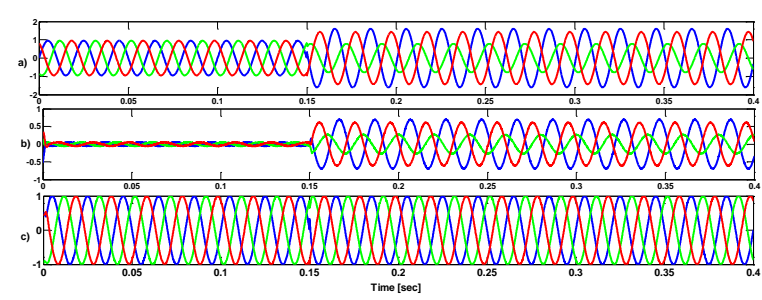

Fig. 9

Figure 10-a and 10-b show the active and reactive injected power for compensation of unbalanced on utility voltage

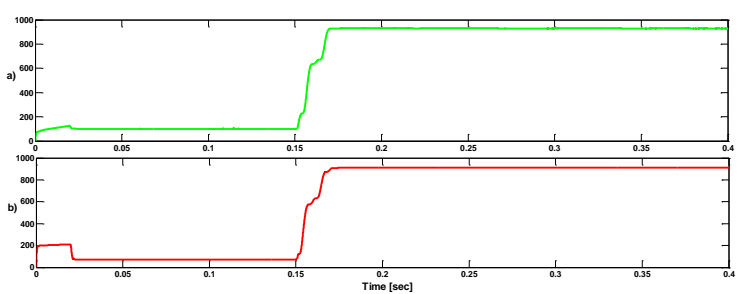

Fig. 10

5.4 Simulation results of 7 th order harmonic occurrence in network voltage

Figure 11-a shows the voltage at PCC, figure $11-\mathrm{b}$ shows the injected voltage of series 
converter, and figure 11-c shows the modified load voltage. Simulation results are shown in the figure.

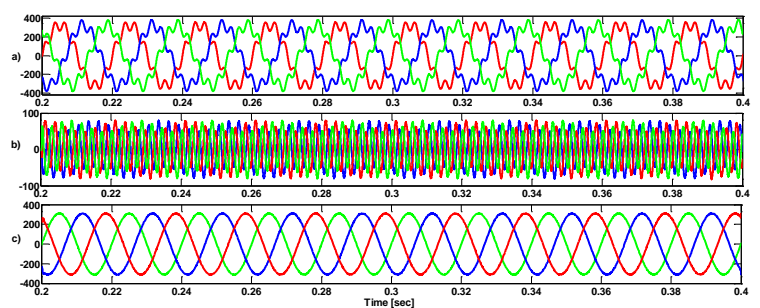

Fig. 11

Figure 12-a and 12-b show the active and reactive injected power for compensation of 7 th order harmonic occurrence in network voltage.

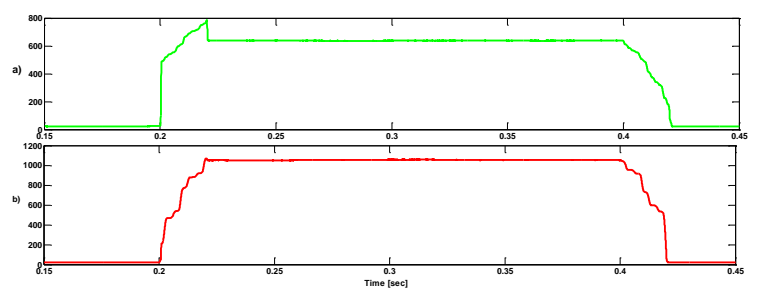

Fig. 12

5.5 Simulation results of three phases to ground short circuit fault

Figure 13-a shows the voltage at PCC, figure 13-b shows the injected voltage of series converter, and figure 13-c shows the modified load voltage in case of three phase short circuit fault.

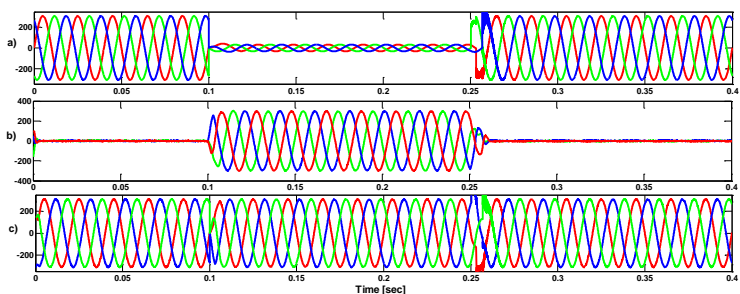

Fig. 13

Figure 14-a and 14-b show the active and reactive injected power for drop voltage compensation in three phase fault case.

As figuras devem estar preferencialmente no formato pdf ou, alternativamente, em ps ou eps. Você pode incluir figuras em seu trabalho. Por exemplo, veja a Figura 1.

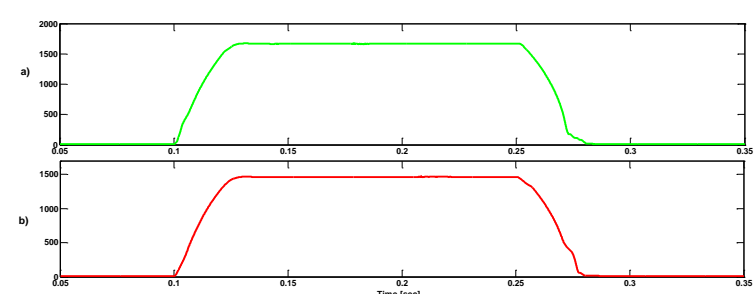

Fig. 14

5.6 Simulation results of two phases to ground short circuit fault

Figure 15-a shows the voltage at PCC, figure $15-\mathrm{b}$ shows the injected voltage of series converter, and figure 15-c shows the modified load voltage in case of two phase short circuit fault.

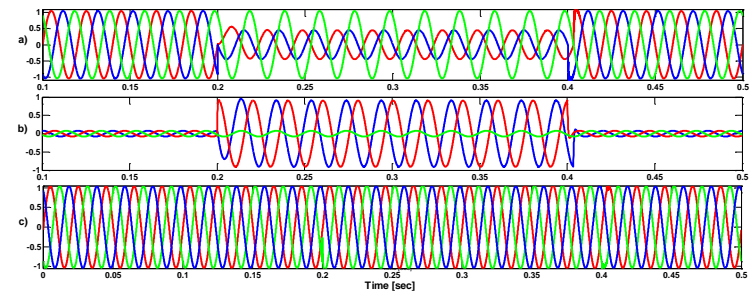

Fig. 15

Figure 16-a and 16-b show the active and reactive injected power for drop voltage compensation in two phase balanced fault case.

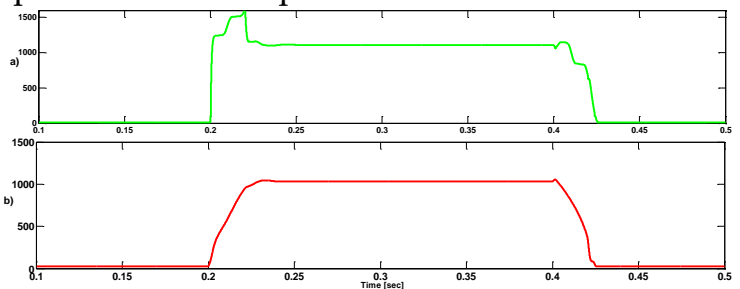

Fig. 16

5.7 Simulation results of single phase to ground short circuit fault

Figure 17-a shows the voltage at PCC, figure $17-b$ shows the injected voltage of series converter, and figure 15-c shows the modified load voltage in case of single phase short circuit fault.

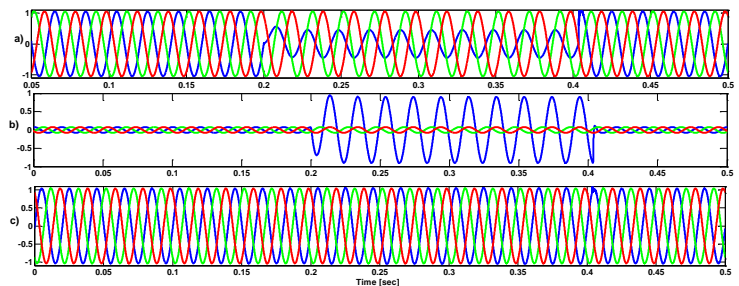

Fig. 17 
Figure 18-a and 18-b show the active and reactive injected power for drop voltage compensation in single phase balanced fault case.

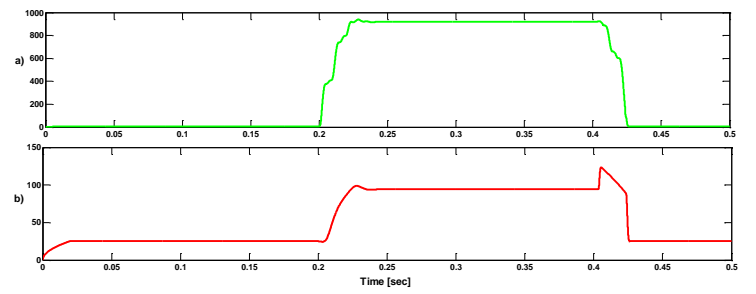

Fig. 18

\section{CONCLUSION}

In this paper, modeling and simulation of AC/DC hybrid microgrids and series converter is conducted and the role of this converter in elimination of voltage sag and swell, balanced short circuit faults, unbalanced source voltage cases, and $7^{\text {th }}$ order harmonic is evaluated. According to the simulation results, the following comments could be summarized:

1- The series converter has an accurate performance against all the voltage faults.

2- The three phases to ground short circuit fault has the maximum injected power; as the number of phases that are short circuit to ground is increased, the more power for the compensation is required.

3- Voltage swell and network harmonics required the minimum power for the compensation.

Therefore, to obtain the desired network voltage that is the sinusoidal voltage with a unit value, the proposed method has the appropriate performance against all the mentioned disturbances.

\section{REFERENCES}

DOE. (2007) "The potential benefits of distributed generation and rate-related issues that may impede their expansion," DOE report.

B. Kroposki, R. Lasseter, T. Ise, S. Morozumi, S. Papathanassiou, and N. Hatziargyriou, (2008) "Making microgrids work," IEEE Power \& Energy Mag., vol. 6, no. 3, pp. 41-53.

M.H. Nehrir, C. Wang, K. Strunz, H. Aki, R. Ramakumar, J. Bing, Z. Miao, and $\mathrm{Z}$. Salameh, (2011)"A Review of Hybrid
Renewable/Alternative Energy Systems for Electric Power Generation: Configurations, Control, and Applications," IEEE Trans. Sustainable Energy, vol. 2, pp. 392-403.

L. $\mathrm{Xu}$ and D. Chen, (2011) "Control and operation of a DC microgrid with variable generation and energy storage," IEEE Trans. Power Del., vol.26, no. 4, pp. 2513-2522.

M. E. Baran and N. R. Mahajan,( 2003)“DC distribution for industrial systemsopportunities and challenges," IEEE Trans. Ind. App., vol. 39,no. 6, pp. 1596-1601.

C. K. Sao and P. W. Lehn, (2008) "Control and power management of converter fed microgrids," IEEE Trans. Power Syst., vol. 23, no. 3, pp.1088-1098.

I.-Y. Chung, W. Liu, D. A. Cartes, E. G. Collins, Jr, and S. Moon.( 2010 )"Control methods of inverter-interfaced distributed generators in a Microgrid system," IEEE Trans. Ind. App., vol. 46, no. 3, pp. 1078-1088.

D. Bo,Y. Li, Z. Zheng, and L. Xu, (EPE 2011) "Control strategies of microgrid with hybrid DC and AC buses," in Proc. 14th Eur. Conf. Power Electron.Appl, pp. 1-8.

N.Eghtedarpour and E.Farjah, (2014)"Power Control and Management in a Hybrid AC/DC Microgrid" IEEE Transanction Smart Grids, VOL. 5 , NO. 3

.C. Sankaran"Power quality", by CRC Press LLC.

D. Graovac, V. A. Katic', and A. Rufer, (2007) "Power quality problems compensation with universal power quality conditioning system, IEEE Trans. Power Deliv., vol. 22, no. 2, pp. 968-976.

B. Singh, K. Al-Haddad, and A. Chandra, (1999) "A review of active filters for power quality improvement," IEEE Trans. Ind. Electron., vol. 46, No. 5, pp. 960-971.

A. G. Cerrada , O. P. Ardila, V. F. Batlle, P. R. Sánchez, and P. G.González.(2007), "Application of a repetitive controller for a three-phase Active power filter," IEEE Trans. Power Electron., vol. 22, no. 1, pp.237-246.

A. Chandra, B. Singh, B. N. Singh, and K. AlHaddad, (2000) "An improved control algorithm of shunt active filter for voltage 
regulation, harmonic elimination, power factor correction, and balancing of nonlinear loads," IEEE Trans. Power Electron., vol. 15,no. 3, pp. 495-507.

1. Zhu, X. Jiang, L. Huang, (2008) "A novel dynamic voltage restorer with wheel energy storage system," ICEMS: Proceedings of the 11th International Conference on Electrical Machines and Systems, pp.1995-1999.

A.O. AI-Mathnani, A. Mohamed, M. A. A. Mohd, (2007) "Photovoltaic based dynamic voltage restorer for voltage sag mitigation," 5th Student Conference on Research and Development, pp. 119-124.

A.M.Rauf (2014) “Integrated Photovoltaic and Dynamic Voltage Restorer System Configuration" IEEE IEEE Trans. Sustainable Energy, 2381291.

Kumar Jena, A.Mohapatra, B.Pradhan, KA.(2006), "Modeling and Simulation of a Dynamic Voltage Restorer (DVR)", Department of Electrical Engineering National Institute of Technology Rourkela, Odisha.

Akaike, H. (1973). Information theory and an extension of the maximum likelihood principle. Em: Proceedings of the 2nd International Symposium on Information Theory, pp. 267-281. 